\title{
A Instrução e a Relação como Modos de Aconselhamento em HIVIAids
}

\author{
Wedna Cristina Marinho Galindo ${ }^{1}$ \\ Departamento de Psicologia da Universidade Federal de Pernambuco, Recife, Brasil \\ Universidade Católica de Pernambuco, Recife, Brasil \\ Ana Lúcia Francisco \\ Departamento de Psicologia da Universidade Católica de Pernambuco, Recife, Brasil \\ Luís Felipe Rios \\ Laboratório de Estudos da Sexualidade Humana da Universidade Federal de Pernambuco, \\ Recife, Brasil
}

\section{Resumo}

O artigo objetiva problematizar a relação profissional de saúde-usuário no aconselhamento em HIV-Aids. Para tanto, apresenta resultados de pesquisa qualitativa, embasada em entrevistas com 12 aconselhadores/as atuando em Centros de Testagem e Aconselhamento em DST/Aids (CTA) de Pernambuco, situados nas mesorregiões do Estado - metropolitana, mata, agreste, sertão. As entrevistas foram audiogravadas e transcritas. $\mathrm{O}$ tratamento e a análise do material foram feitos a partir de uma dupla hermenêutica. Identificamos, no material, dois modos de aconselhar: o aconselhamento-instrução e o aconselhamento-relação. No aconselhamento-instrução a ênfase é na transmissão de informações do profissional ao usuário, sendo este, considerado responsável por sua condição sorológica. No aconselhamento-relação, valoriza-se o contato do profissional com o usuário, oferecendo-lhe escuta e acolhida. Os resultados além de contribuírem com os debates sobre a abordagem e o manejo das noções de risco e sexualidade, no aconselhamento, podem auxiliar na formação de aconselhadores.

Palavras-chave: Aconselhamento, Síndrome da Imunodeficiência Adquirida, profissional de saúde, capacitação de recursos humanos em saúde.

\section{Instruction and Relation as Ways of Counseling in HIVIAids}

\begin{abstract}
The paper purpose is problematize the professional relation of health-user in the counseling in HIV-Aids. For this purpose, present results from qualitative survey, based in interviews with 12 advisors acting in Centers of Tests and Counseling in DST/Aids (CTA) of Pernambuco, located in the mesoregions of the State-metropolitan areas, specific areas like: mata, agreste, sertão. The interviews were recorded and transcribed. The treatment and analysis of the material were done from a hermeneutic pair. We identified two ways of counseling. In the counseling-education the emphasis is in the transmission of information from the professional to the user, being his/her, considered responsible for his serological condition. In the counseling-relation, the professional contact goes up in value with the user, offering listening and
\end{abstract}

Endereço para correspondência: Rua Sete de Setembro, 365/1002, Boa Vista, Recife, PE, Brasil 50050-030. E-mail: wedna.galindo@gmail.com

Este trabalho recebeu financiamento da Fundação de Amparo ao Desenvolvimento Científico do Estado de Pernambuco (Facepe), a partir de Bolsa de Doutorado. 
refuge. The results besides contributing with the discussions on the approach and the handling of the notions of risk and sexuality, in the counseling, can help in the advisors' formation.

Keywords: Counseling, Acquired Immunodeficiency Syndrome, health personnel, health human resource training.

\section{La Instrucción y la Relación como Modos de Aconsejamiento en HIVISIDA}

\section{Resumen}

El presente artículo tiene como objetivo problematizar la relación profesional de salud-usuario en el aconsejamiento en HIV-SIDA. Para esto, se presentan resultados de investigación cualitativa, basada en entrevistas hechas con 12 aconsejadores/as que actúan en Centros de Testeo y Aconsejamiento en los DST/SIDA (CTA) de Pernambuco, ubicados en las mesorregiones del Estado: la metropolitana, la zona de mata, el agreste y el sertón. Las entrevistas fueron audiograbadas y transcritas. El tratamiento y el análisis del material fueron realizados a partir de una doble hermenéutica. Identificamos dos modos de aconsejar: el aconsejamiento-instrucción y el aconsejamiento-relación. En el aconsejamiento-instrucción, el énfasis se hace en la transmisión de informaciones del profesional al usuario, siendo éste considerado como el responsable por su condición serológica. En el aconsejamiento-relación, se valoriza el contacto del profesional para con el usuario, así como la atención y acogida que le proporciona. Los resultados, además de contribuir con los debates sobre el abordaje y el manejo de las nociones de riesgo y sexualidad, en el aconsejamiento, pueden auxiliar en la formación de los aconsejadores.

Palabras clave: Aconsejamiento, Síndrome de Inmunodeficiencia Adquirida, personal de salud, capacitación de recursos humanos en salud.

A Síndrome da Imunodeficiência Adquirida (Aids) tem convocado pesquisadores, gestores, profissionais de saúde a encontrar respostas efetivas para o seu enfrentamento. No início dos anos de 1980, no Brasil, diante dos primeiros casos de Aids, grupos da sociedade civil, em especial de hemofílicos e gays, buscaram gestores públicos para somar esforços na compreensão e soluções para o problema. São de iniciativa da sociedade civil as primeiras experiências com aconselhamento em HIV/Aids (Araújo \& Camargo, 2004; Parker, 2000).

Preconizado para ser realizado por profissional de saúde capacitado para tal, o aconselhamento acompanha o exame anti-HIV, ocorrendo antes da coleta do sangue (pré-teste), e na entrega do resultado (pós-teste). Conforme os documentos do Ministério da Saúde que orientam a prática do aconselhamento, esta deve se caracterizar por um espaço de diálogo no qual são disponibilizadas informações, realizada avaliação de riscos e oferecido apoio emocional (Ministério da Saúde, 1993, 1998, 1999).
No início da história da aids no Brasil, o aconselhamento serviu como ferramenta de controle de qualidade para os Bancos de Sangue, já que muitas pessoas tinham a iniciativa de doar sangue com objetivo não explícito de serem testadas para o HIV. Um atendimento com o pretenso doador identificaria riscos recentes restringindo doadores. (Araújo \& Camargo, 2004; Ministério da Saúde, 1999). Hoje há uma tendência em disponibilizar amplamente a testagem e o aconselhamento, cujas unidades de referências são os Centro de Testagem e Aconselhamento em DST/ Aids (CTA; Ministério da Saúde, 2010).

Em 1987, o Ministério da Saúde iniciou treinamento de profissionais para aconselhamento e em 1988 começou a implantação de CTAs (Araújo \& Camargo, 2004). A partir de 2003 instala-se processo de descentralização da testagem para o HIV, sendo assumida também pela atenção básica de saúde, com a recomendação de garantir o aconselhamento (Ministério da Saúde, 2003).

Diretrizes formuladas recentemente para o trabalho nos CTAs (Ministério da Saúde, 2010), 
acrescentam duas recomendações em relação ao preconizado até então. Que o aconselhamento seja disponibilizado não apenas na testagem anti-HIV, mas para a população envolvida com a temática, que busca as unidades de saúde, como casais (soroconcordantes ou sorodiscordantes); pessoas vivendo com HIV e Aids (PVHA); portadores de hepatites e familiares; pessoas que aguardam resultado de exames (hepatites, HIV, sífilis); pessoas que aguardam encaminhamento para unidades de referência. E que o aconselhamento seja assumido também por profissionais de formação de nível técnico, e não só superior, desde que devidamente capacitados para tal.

Em pesquisa de avaliação das ações de aconselhamento, ainda em 1997, Filgueiras e Deslandes (1999, p. 129) observando e entrevistando profissionais e usuários do Sistema Único de Saúde (SUS), analisaram a referida prática a partir de cinco diretrizes reconhecidas pela literatura de então: (a) acolhimento; (b) escuta; (c) comunicação; (d) avaliação de riscos e alternativas para prevenção; (e) orientações sobre tratamento para estimular adesão e qualidade de vida. As autoras concluem, dentre outros aspectos, que os profissionais desenvolvem bem a acolhida aos usuários, o que não se deve confundir com "uma atitude de verdadeira escuta. Observou-se que a atitude de escuta foi frequentemente substituída pelo caráter informativo (visto como instrução ou orientação informativa de caráter normativo) e de coleta de dados sobre o paciente". Sugerem ainda, as autoras, que o apoio e a supervisão aos profissionais aconselhadores qualificariam a sua rotina de trabalho que tende a ser de intenso estresse.

Avaliações como esta possibilitam reflexões e revisões do serviço oferecido pelo profissional de saúde, mas trata o aconselhamento, especificamente, como técnica. Neste trabalho estamos considerando o aconselhamento como dispositivo no quadro de respostas ao HIV/aids. O dispositivo, tal como argumenta Michel Foucault (2007a) envolve diversos aspectos como discursos, leis, instituições, enunciados científicos, proposições morais e assume função estratégica dominante, em determinado momento histórico. A relação entre os diversos elementos heterogêneos de um dispositivo, é que merece atenção.
"Entre esses elementos, discursivos ou não, existe um tipo de jogo, ou seja, mudanças de posição, modificações de funções" (p. 244).

Nesta direção, a pesquisa sobre os discursos do aconselhamento em CTA empenhada por Souza e Czeresnia (2007, p. 545) conclui que parece existir, no aconselhamento, um "jogo de ambiguidades entre sistema democrático e coercitivo, conjugando modos informais e regulatórios" na relação entre profissional de saúde e usuário. Isto é, o aconselhamento envolve atenção, acolhida, escuta e, ao mesmo tempo, regulação, vigilância, controle. Pode ser considerado, portanto, uma tecnologia leve (Merhy, 2007), implicada com a gestão do cuidado e, também, uma prática confessional, disciplinar, de biopoder (Foucault, 2007b).

Soma-se ao quadro de referências que cercam o aconselhamento como dispositivo, o que acumulamos em nossa recente história quanto às tentativas de responder ao HIV/aids. Richard Parker (2000, pp. 65-66) apresenta três tendências ou abordagens da produção científica no campo da aids "que parecem haver emergido em nossas tentativas de analisar e responder às dimensões sociais da epidemia": (a) Estudo de padrões de comportamento relacionados à transmissão do HIV, que surgiu a partir de meados dos anos de 1980; (b) Estudo de estruturas culturais e sociais implicadas nos comportamento de risco de infecção pelo HIV, que ganhou espaço a partir de meados e final dos anos de 1980; (c) Estudo com ênfase em fatores políticos e econômicos associados à disseminação do HIV, desde o final dos anos de 1990 até hoje. Essas tendências na pesquisa científica têm orientado, respectivamente, a formatação de políticas: (a) para intervenções sobre o comportamento; (b) para a construção de programas de prevenção tendo como base conhecimento sócio antropológico; (c) com respostas mais globais e de longo prazo, a partir da compreensão da complexidade do fenômeno e tendo como meta "transformar as forças mais amplas que estruturam a vulnerabilidade ao HIV/Aids" (Parker, 2000, p. 26). A prática do aconselhamento inscreve-se nesse cenário de esforços para propor respostas efetivas e eficazes ao HIV/aids, sendo também influenciada pelas 
diversas tendências em pesquisa e formatação de políticas.

Neste estudo discutimos sobre como profissionais de saúde significam sua prática de aconselhamento em CTA. Apoiada em perspectiva crítica tanto nos fundamentos teóricos quanto na orientação da pesquisa, a pesquisa se compromete com a produção de um "conhecimento pragmático, prático, que seja cultural e estrutural, avaliado pelo seu grau de situacionalidade e sua habilidade de gerar práxis, ou ação" (Denzin \& Lincoln, 2006, p. 166). Assim, distanciamo-nos de referenciais ligados ao cientificismo positivista em psicologia e em ciências humanas, identificando que esta perspectiva tem se comprometido com a manutenção do quadro de desigualdades sociais comuns nas sociedades capitalistas (Mészaros, 2004; B. S. Santos, 2000). Além disso, baseamos nosso estudo em perspectiva crítica da pesquisa qualitativa, alternativa ao eurocentrismo das construções intelectuais e em direção ao fortalecimento de construções pós-coloniais sobre a realidade latino-americana e por pesquisadores latino-americanos (Grüner, 2011; B. S. Santos, 2010)

\section{Metodologia}

Trata-se de uma pesquisa clínico-qualitativa que, conforme aborda Turato (2003), tem especificidades em relação às abordagens qualitativas gerais. "Os sentidos e as significações dos fenômenos são o cerne para os pesquisadores qualitativistas. Procurar capturá-los, ouvindo e observando os sujeitos de pesquisa, bem como dar as interpretações, são nossos objetivos maiores" (p. 246). Além das clássicas características da pesquisa qualitativa - naturalística, dados descritivos, foco no processo, indutiva, ênfase na significação - outras são atribuídas à abordagem clínico-qualitativa. Destacamos, dentre elas, a função do pesquisador como instrumento principal na investigação e como bricoleur ao lidar com a pesquisa. O pesquisador participa ativamente da construção da pesquisa na sua formatação, coleta, análise dos dados e apresentação dos resultados. Sua percepção, reflexão, aspectos emocionais colocam-se à disposição da investigação, o que resulta em posicionalmente oposto às pesquisas que se utilizam de instrumentos validados, como as quantitativas. Além disso, como bricoleur, o pesquisador compõe o seu conhecimento a partir de fragmentos obtidos no campo, permitindo-se, inclusive, a colocar em suspenso o projeto inicial. Denzin e Lincoln (2006) associam o pesquisador bricoleur a um artesão que confecciona colchas ou um produtor de filmes; a tarefa em questão é como a de montagem de um quebra-cabeça.

Foram realizadas entrevistas, individualmente, com 12 aconselhadores, sendo $11 \mathrm{mu}-$ lheres e um homem ${ }^{2}$. Com idades entre 25 e 57 anos, todas entrevistadas tinham formação superior, oito delas em Psicologia, três em Serviço Social e uma em Biologia. Os aconselhadores participantes da pesquisa trabalham em CTAs de municípios das diversas macrorregiões do estado de Pernambuco. Foram realizadas três entrevistas em cada uma das quatro macrorregiões: sertão, agreste, mata e metropolitana. O esforço foi de escutar profissionais atuando em diversos territórios do Estado. Orientou nossa estratégia, a perspectiva geográfica na produção de subjetividades (Ferreira, 2011), ainda que tal elemento não se configurasse como condição a priori para coleta de dados.

O projeto de pesquisa foi aprovado pelo Comitê de Ética da Universidade Católica de Pernambuco (Unicap). A entrevista foi antecedida pela leitura e assinatura do Termo de Consentimento Livre e Esclarecido (TCLE), pelas participantes. Com duração média de 40 minutos, cada entrevista foi audiogravada e, posteriormente, transcrita literalmente.

A leitura flutuante do material (Bardin, 1977) possibilitou a construção da estratégia de tratamento dos dados descrita a seguir. Recursos de copiar, colar, recortar, classificar, de editor eletrônico de texto foram utilizados no tratamento dos dados (Galindo, 2008; Kelle, 2002).

Na primeira etapa traçamos quatro Planos de Análise, considerando os fluxos temáticos das entrevistas. Os Planos foram: (a) Usuários-

\footnotetext{
Trataremos as pessoas entrevistadas, ora pelo masculino, ora pelo feminino.
} 
refere-se a quem procura o CTA; (b) Profissionais - quem faz o aconselhamento; (c) Aconselhamento - corresponde ao aconselhamento propriamente dito, ao que ocorre na relação profissional-usuário; (d) Trabalho - reúne questões associadas ao trabalho em saúde de forma geral (gestão, concepções de saúde, políticas). Os fragmentos de fala foram identificados aos planos, de modo que ao final dessa primeira etapa, tínhamos quatro blocos de materiais, cada um correspondente a um Plano, contendo as falas de todas as entrevistas a ele associadas.

$\mathrm{Na}$ segunda etapa do tratamento dos dados cada Plano de análise - com todos os fragmentos de fala agrupados - passou por um novo processo analítico. Após leitura flutuante, identificaram-se conteúdos que emergiram de cada Plano. Os conteúdos subsidiaram o novo ordenamento do material, agora por temas. Assim, por exemplo, no Plano Usuário quatro temas/conteúdos foram organizados, nesta segunda etapa do tratamento dos dados. O mesmo procedimento foi feito para os outros três planos, cujos conteúdos/ temas estão discriminados a seguir:

1. Plano Usuário: (a) Quem é a população que procura o CTA; (b) Sentimentos expressos pelos usuários; (c) Concepções e práticas dos usuários em torno de riscos; (d) Demandas dos usuários.

2. Plano Profissional: (a) Características do aconselhador; (b) Processos formais e informais para realizar aconselhamento; (c) Postura/Manejo na relação com o usuário; (d) Sentimentos, concepções, interesses do profissional em relação à sua prática e aos temas implicados.

3. Plano Aconselhamento: (a) Modalidades de aconselhamento utilizadas no CTA; (b) Abordagem das práticas sexuais junto aos usuários; (c) Procedimentos envolvidos na entrega de resultados; (d) Relação profissional-usuário propriamente dita.

4. Plano Trabalho: (a) Rotina interna do CTA; (b) Atividades externas ao CTA; (c) Recursos envolvidos; (d) Política de saúde e gestão.

A terceira etapa do tratamento dos dados foi a redação de sínteses dos conteúdos que emergiram em cada um dos planos traçados. Várias leituras das sínteses antecederam o rascunho inicial da análise. Redações provisórias deram lugar ao texto final aqui apresentado. A interpretação qualitativa dos dados foi feita por uma dupla hermenêutica que segundo Deslandes e Gomes (2004) consiste em reinterpretar as interpretações dos sujeitos envolvidos na pesquisa. Assim, nossa "análise não se volta, por exemplo, ao modo como determinado profissional atende ao usuário (a isso caberiam dezenas de hipóteses explicativas), mas a como ele interpreta essa forma de atender e quais lógicas culturais e institucionais dão sentido e racionalidade a essa maneira de explicar a sua própria ação" (p. 109).

\section{Modos de Aconselhar}

Os modos de aconselhar identificados instrução e relação - são apresentados em separado, como recurso de perseguir clareza na apresentação das ideias. Entretanto, não devem ser considerados como tipos ideais e excludentes entre si, mas como possibilidades de convivência num mesmo CTA e assumidos por um mesmo aconselhador. Assim, não foi objetivo do estudo associar os entrevistados aos modos de aconselhar.

\section{O Aconselhamento Instrução}

Caracteriza-se pela transmissão de informações por parte dos profissionais, aos usuários. Estes são convocados, dentre outros aspectos, a tomar consciência da importância da prevenção, de corrigir o uso inadequado do preservativo ['estoura porque o fato de você não está sabendo utilizar' ${ }^{3}$, diz entrevistada a usuário] e de entender que realizar o teste não é garantia de proteção. Além disso, disponibiliza-se 'orientação com relação à higiene, porque muitos são pacientes, assim, muito pobres, pessoas que não têm a mínima estrutura de nada'. O usuário, então, é o responsável por sua condição sorológica. Espera-se dele habilidades para serem usadas no aconselhamento - apreensão e memorização das

Fragmentos de fala das entrevistadas ilustram a apresentação dos resultados. Utilizamos aspas simples e itálico para destacá-las do texto. 
instruções fornecidas pelo profissional. A esse respeito, as entrevistadas indicam que alguns usuários vão tomando consciência da importância do autocuidado, enquanto outros sequer têm condições para entender as instruções, sem deixar de mencionar expressões de resistência diante das orientações. Sentimentos dos usuários são destacados nesse contexto, como medo da quebra de sigilo; vergonha em assistir à demonstração no uso do preservativo; medo de pegar HIV por formas improváveis.

As tarefas de educar, orientar, além de manter-se em postura vigilante são associadas ao profissional. 'Se uma pessoa tá passando pela situação de receber um resultado positivo . . . é um sujeito que é, digamos assim, ela é corresponsável por isso ai também'.

No aconselhamento instrução os cuidados para com o atendimento prestado ao usuário como: local e horário adequados, garantia de sigilo, transmissão de segurança, parecem estar a serviço do compromisso em transmitir informações e da expectativa de que o usuário fale de si, para ser avaliado quanto ao risco de infecção pelo HIV. O profissional deve conduzir o atendimento de modo que o usuário venha 'adquirir confiança sobre [ele]'. Assim, os entrevistados parecem considerar que o informado pelo aconselhador será internalizado pelo usuário, de forma mais eficaz.

Os esforços em garantir que a informação chegue ao usuário, no aconselhamento instrução, se traduzem por arranjos estratégicos na rotina do trabalho. Assim, o aconselhamento pré-teste, no CTA, pode ser individual ou coletivo. Também pode ser realizado fora do CTA, por demanda espontânea de empresas, escolas e organizações diversas ou por planejamento prévio da política municipal de aids. Merecem destaque ações realizadas em datas comemorativas e/ou em bairros/distritos rurais, cuja testagem e aconselhamento são disponibilizados à população ${ }^{4}$, na perspectiva de, ao mesmo tempo em que facilita o acesso ao teste, examina um grande número de pessoas.

4 Daqui por diante chamadas apenas de "ações de massa".
Ajustes na rotina de trabalho - dentro e fora do CTA -, indicam uma ênfase na testagem anti-HIV, em detrimento do aconselhamento já que este parece ficar em segundo plano, sendo a prioridade dirigida à testagem. Isso é exemplificado no seguinte relato de aconselhador em seu diálogo com usuário, criticando o tempo restrito para o aconselhamento: '- Pois é, o resultado deu negativo; não reagente quer dizer negativo, viu? Entendeu? - Entendi. - Alguma dúvida? - Não. - Bom dia. E não é [não deve ser] assim'. De forma geral, para atender a demanda de testagem, o aconselhamento pré-teste pode também ser subtraído, sendo reservado ao aconselhamento pós-teste a atenção para informações, avaliação de riscos, apoio emocional.

Assim, o aconselhamento pode ficar comprometido nas diversas situações em que é priorizada a testagem. Nas ações de massa, muitas vezes, até o pós-teste fica a desejar; o que ocorre é 'colhe, preenche aquela ficha, aquele cadastro, $e$ [a entrega de] o resultado é assim: 'Tá tudo bem, tá tudo bem'. Nesses casos, 'eu acredito que o próprio aconselhamento fica um pouco a desejar, por conta da demanda que é muita'.

São realizadas tentativas de alterar esse quadro, mas, quando o aconselhamento ocorre fora do CTA, o trabalho mantém os profissionais dependentes de infraestrutura oferecida por quem demandou a ação.

No ano passado a gente só fazia preencher a ficha, fazia o exame, entregava, tchau. Esse ano a gente já pediu pra fazer aconselhamento. Não é aconselhamento que se faz aqui, porque é no salão; fica entrando [pessoas], ai tem que ficar bem assim [junto, cochichando] com o paciente.

Em consonância com esse quadro de fragilidade na prática do aconselhamento, estão aspectos do trabalho propriamente dito. O recrutamento e seleção de aconselhadores para o CTA não considera aspectos específicos do trabalho nesta unidade de saúde. Os profissionais são selecionados por concurso público para área geral de saúde; as vagas não são identificadas pelas diferentes possibilidades de atuação. Outra forma de ingresso no trabalho como aconselhador no CTA é por convite, comum em municípios 
nos quais vagas por concurso público ainda são reduzidas. $\mathrm{O}$ ingresso no CTA por convite pode não selecionar as pessoas por características/habilidades para o trabalho. Ao contrário, esse tipo de contratação é vulnerável às alterações políticas de cada mandato do executivo municipal. 'Quando essa gestão acabar mudam todas as pessoas'. Isso pode fragilizar a política municipal de HIV-aids, já que a alta rotatividade de aconselhadoras desagrada usuários, que a cada visita ao CTA não encontra a pessoa que o atendeu da última vez.

A formação de aconselhadores nesse contexto torna-se cara e obsoleta, pois sempre novos aconselhadores estão assumindo essa função e demandando nova formação. 'A gente vem mudando [de aconselhador] o tempo todo e o tempo todo eu venho pedindo o treinamento de aconselhamento'.

As características e/ou ferramentas associadas aos aconselhadores como importantes para realização de suas tarefas no aconselhamento instrução nos informam de um modelo convencional de relação profissional-usuário, na qual o profissional transmite, informa e o usuário recebe, apreende. Algumas características do profissional ganham destaque para a execução do aconselhamento, embora prevaleçam as pautadas em aspectos relacionadas mais ao senso comum (intuição, sensibilidade, instinto), do que propriamente à formação/postura profissional. Explicitam isso os seguintes fragmentos de fala: 'eu tenho, sei lá, um instinto maternal'; 'eu sou muito intuitiva'; 'eu acho que esse profissional tem que ter muita sensibilidade'.

Ao aconselhamento instrução, portanto, parecem se articular elementos comprometidos com perspectiva naturalizante tanto do comportamento de usuários, quanto do trabalho dos profissionais.

\section{O Aconselhamento Relação}

Outro discurso apresenta o aconselhamento como construção entre profissional da saúde e usuário. Da parte do usuário, é um momento de reflexão. Da parte do profissional, uma construção pessoal, já que não há modelo pronto para aconselhamento, cada caso demandando espe- cificidades. Nessa relação, ao usuário deve-se disponibilizar tempo para que possa elaborar a situação diante de si, seja de soronegatividade ou soropositividade. Ao profissional cabe escutar o usuário em sua singularidade. 'A gente vem de um modelo muito normativo, de regras prontas ... A proposta [do aconselhamento] é uma proposta de mudança de paradigma mesmo. . . . Então, a gente precisa se distanciar do método, para escutar'. Em algumas situações, 'não há nem diálogo' entre profissional e usuário, cabendo àquele silenciar diante do processo cujo protagonismo é de quem está sendo acolhido. 'Escuto mais do que questiono' indica uma entrevistada ao argumentar que o aconselhamento envolve participação ativa do usuário.

$\mathrm{O}$ sujeito do aconselhamento relação, de acordo com o que dizem os entrevistados, é dinâmico, tem sentimentos, medos, fantasmas, dúvidas, tem uma intimidade consigo e merece atenção e cuidado para que sejam abordadas situações que envolvam as vivências em torno da sexualidade. É nesse sentido que aconselhadoras se esforçam em criar espaço para 'você conseguir que ela [usuária] fale... [para saber] o que ele [usuário] tá querendo, o que tá incomodando ele, no que eu posso ajudar em relação ao aconselhamento'.

Compreende-se que a mera transmissão de informações é insuficiente para garantir a efetividade do aconselhamento. 'Se a informação resolvesse a gente não tinha epidemia; que a informação circula! Tem que ter uma coisa mais profunda'. Assim, é importante entender como o usuário significa sua realidade no contexto do HIV-aids, já que isso pode estar presente na cena do aconselhamento.

A noção de risco e a percepção do que oferece risco, por exemplo, podem ser incompatíveis com o que temos historicamente construído pelo saber formal sobre infecção pelo HIV. Os usuários tendem a repetir o termo risco, sem a devida atenção às implicações em sua própria vida.

Quando ela [usuária] falou eu tô tendo risco, ela não tinha pensado naquilo pra dizer. Ela ouviu por aí, [então diz:] tive uma situação de risco. Mas, que risco é esse que ela tá tendo na vida dela, no cotidiano dela? 
Em municípios do interior do Estado há quem acredite que pega aids somente quem morou em São Paulo, isto é, quem migrou para uma cidade grande em busca de trabalho, realidade comum em alguns territórios. 'Quando a gente fala na palestra, no aconselhamento coletivo [que não é só quem morou em São Paulo que pode ter HIV], todo mundo fica muito assustado'.

No aconselhamento relação, os profissionais tendem a considerar que a reprodução acrítica da noção de risco ou a crença em formas improváveis de infecção - como a migração - são expressão de arranjos simbólicos por parte dos usuários. Isto é, são noções, ao mesmo tempo, construídas no social, e constituidoras dos sujeitos. A postura do profissional de saúde, de acordo com a opinião das entrevistadas nesse caso, deve ser marcada por atenção e manejo delicados, que dialoguem com o universo simbólico envolvido.

As relações sociais construídas em torno da diferença de gêneros também constituem valores e modos específicos de lidar com a realidade.

Brasil é muito assim, cada lugar tem... nordeste então... que o homem é garanhão, que o homem tem que ser macho, né? Que o homem tem várias mulheres, que o homem não usa camisinha, porque ele não fica doente, ele não pega doença.

Também tem a história do Brasil vem de uma raiz cristã ... Quais as religiões que existem no Brasil que abordam o sexo, que se conversa mais sobre o sexo . . Porque vem dessa coisa velada, talvez por conta dessa raiz cristã.

Assim, diferenças da percepção e/ou comportamento que podem levar à infecção de DST são identificadas por homens e mulheres também sob a lógica dessas construções culturais. Os homens tendem a se sentirem protegidos em seus relacionamentos sexuais; confiam na parceria; compartilham o valor de que o casamento protege. Tem homens que dizem, segundo entrevistada: 'Eu só transo com minha esposa e quando eu transo com outra pessoa lá fora é as meninas conhecidas. É tudo conhecida e elas dizem que não têm isso não'.
As mulheres estão mais vulneráveis à possibilidade de infecção pelo HIV a partir dos arranjos afetivo-sexuais dos quais participa. Como os homens, também têm fantasias de proteção, mas, estas se organizam em torno do afeto e da própria fidelidade. É assim, por exemplo, que prostitutas usam preservativos com clientes, mas não usam com parceiro fixo, de acordo com relato de entrevistada. Como expressão da dominação do masculino, várias situações são encontradas. 'Ou transa com esse cabra sem camisinha ou não tem nem o que comer', diz entrevistada. São relatadas situações de violência sexual à mulher e de exploração sexual de crianças e adolescentes, cuja autoria é de homem adulto com vivência doméstica das vítimas.

As construções sociais a que se referem os entrevistados fazem parte da cena do aconselhamento relação como verdades que se impõem aos usuários e se presentificam no diálogo com os aconselhadores.

No aconselhamento relação identificamos duas posturas interventivas diferentes por parte dos profissionais. Uma, que lembra o aconselhamento instrução, em que a aconselhadora esclarece, orienta, entendendo e acreditando que, por exemplo, "na hora que eu [usuária] tenho uma relação sexual sem camisinha, eu sou parceira, eu tenho $50 \%$ de culpa nessa história. Porque às vezes elas dizem 'eu mato meu marido' [se pegar HIV]. Não [diz aconselhadora], você consentiu também'. Então, apesar da aparente postura crítica na compreensão da situação, a eficácia da intervenção fica - como no aconselhamento instrução - dependente da usuária; restrita à sua própria consciência que, no caso do fragmento ilustrativo, trata-se de mulher em relação heterossexual fixa. A ideia de que o comportamento e opinião expressos estão articulados com construções sociais em torno das diferenças de gênero, nesse caso, não é considerada pelos aconselhadores.

A segunda direção da intervenção não se apressa em propor um modelo, uma técnica a ser adotada no aconselhamento e/ou para compreender a situação trazida pela usuária. Ao contrário, o aconselhamento é visto como uma construção. O desafio é o de uma verdadeira 'mudança de 
paradigma', distanciando-se de um modelo normativo, de ideias preconcebidas no que se refere às temáticas envolvidas. A condição de vulnerabilidade da mulher, por exemplo, em relações afetivo-sexuais, é compreendida como implicada nas construções sociais. A solidão da mulher no que se refere à responsabilidade da gravidez tem historicamente construído um abismo no diálogo com seu parceiro sobre contracepção, agora atualizado no uso do preservativo, na prevenção de DST.

A camisinha é uma coisa da parceria; e isso não é muito praticado... isso tem a ver com essas construções... essa vivência solitária, de que é só da mulher a responsabilidade... Então isso precisa mudar, pra gente chegar na própria ação.

No que se refere às questões mais amplas do trabalho em saúde, identificamos reflexões críticas quanto ao aconselhamento disponibilizado no CTA à população. Na lógica do aconselhamento relação identifica-se que interesses políticos orientam relação da gestão municipal com o CTA. Considera-se que o apoio da gestão é imprescindível para qualificar o atendimento à população. É por decisão política, por exemplo, que se investe em prevenção ou, ao contrário, opta-se por realizar grande quantidade de testes sem se preocupar com o aconselhamento. A relação dos profissionais de saúde com a gestão também se inclui nesse tópico. Contratados por concurso público têm mais autonomia do que aqueles com cargo comissionado, podendo negar-se a executar procedimentos com os quais não concordam.

No aconselhamento relação, o desafio de enfrentamento da aids parece envolver desde a formação de profissionais até a compreensão e posicionamento crítico diante de questões econômicas típicas do sistema capitalista. Assim, distancia-se de perspectivas que reduzem aos indivíduos a responsabilidade por contrair o HIV, incluindo elementos para além de uma interioridade, implicados no quadro de vulnerabilidade com o qual convivem os usuários. Identificamos iniciativas em formar profissionais que atuam na atenção básica, para acolherem demandas ligadas às práticas sexuais, segundo diretrizes que orientam o aconselhamento. Também foram citados projetos de fortalecer o diálogo com espaços de formação de profissionais de saúde (cursos técnicos e de nível superior), no sentido de que incorporem em seus currículos, atenção ao aconselhamento como prática em saúde coletiva.

\section{Desafios na Prática do Aconselhamento}

As duas perspectivas de aconselhamento identificadas na pesquisa - o aconselhamento instrução e o aconselhamento relação - informam sobre posturas diferenciadas na concepção de sujeito e nos procedimentos de profissionais de saúde, que, por conseguinte, indicam estratégias distintas na eleição de tecnologias para a construção de respostas ao HIV/aids.

No aconselhamento instrução a intervenção é inspirada numa psicologia individual, isto é, reduzida ao sujeito que recebe orientações e apoio do profissional de saúde. Essa estratégia identificada em pesquisa do final dos anos 1990, em unidades de saúde referência em DST-Aids (Filgueiras \& Deslandes, 1999), continua então, presente no cotidiano dos CTAs e reproduz as tendências intervencionistas comuns nos anos iniciais (na década de 1980) das primeiras respostas à aids. Essa perspectiva de que algumas pessoas poderiam, por características pessoais, contrair o HIV, orientou tanto a produção científica quanto a formatação de políticas (Ayres, França, Calazans, \& Saletti, 2003; Parker, 2000).

Mudanças no perfil epidemiológico da Aids, bem como autocrítica de pesquisadores, gestores e profissionais constataram que aquela perspectiva tinha impacto reduzido na situação, além de ser reprodutora de preconceito e estigma. "Quando o comportamento do indivíduo é trazido para o centro da cena, a consequência inevitável é que se atribua à displicência pessoal, para dizer o mínimo, a eventual falha na prevenção" (Ayres et al., 2003, p. 121).

A ênfase na responsabilização do indivíduo parece impossibilitar um posicionamento crítico por parte de aconselhadores, no sentido de 
considerar outras forças implicadas na realidade em foco. A concepção de sua própria rotina de trabalho e realidade profissional sugere uma atenção às obrigações a cumprir, em detrimento da dinâmica de vida do sujeito à sua frente. É nesse sentido que associamos o aconselhamento instrução à lógica capitalista de trabalho e de organização da sociedade. A divisão social do trabalho em saúde, marcada pelo cumprimento de metas, horários, produtividade, parece se impor aos aconselhadores, cujas tarefas de escutar e acolher ficam comprometidas (Santos-Filho, 2009; Traverso-Yépez, 2008). Ao contrário, os profissionais ocupam-se em preencher questionário, coletar sangue, transmitir informações, orientar testagem de parceiros/as sexuais, encaminhar para outras unidades. "A subjetividade não faz parte da técnica. Ela está presente nas consultas médicas; porém, em geral permanece quase 'invisível'" é o que constata D. F. Santos (2009, p. 99) em sua pesquisa de mestrado sobre formação médica para acompanhamento de pessoas vivendo com HIV/aids.

O usuário entra num circuito que se assemelha à produção industrial de entrada de insumos e saída de produtos. Espera-se que o profissional de saúde seja o agenciador desse processo. "A racionalidade técnica, ao eliminar os elementos subjetivos do processo de trabalho, incide na qualidade do atendimento em saúde, desvitalizando a relação profissional-usuário", conclui Monteiro e Figueiredo (2009) em estudo sobre atuação profissional no campo do HIV-aids.

Na nossa realidade, a divisão social do trabalho em saúde, inspirada no modelo biomédico, tem definido como tarefa do profissional de saúde com formação universitária, de forma geral, as ações de diagnosticar, medicar, curar. "O que caracteriza a normalização da sociedade pela medicina é o fato de ela agregar à sua função de cura uma função política de criar e transmitir normas" (Corrêa, 1994, p. 119).

No caso dos CTAs - unidades de referência para diagnóstico de HIV - convive-se com o risco de se priorizar a testagem em detrimento do aconselhamento. Considerando que este se caracteriza em tese, pela escuta e diálogo, distancia-se do que recomenda o modelo biomédico hegemônico. Assim, no campo de forças que se instala na rotina do serviço, o aconselhamento tende a ser menos valorizado.

Talvez a forte presença dessa perspectiva biomédica esteja orientando as ações de massa, isto é, de ampla testagem, também chamadas de mutirões, situações em que o aconselhamento fica reduzido e, às vezes, subtraído. Essa tendência em priorizar a testagem parece se constituir em expressão do biopoder, isto é, do controle dos corpos, garantido pela responsabilização e culpabilização dos indivíduos. A primazia da testagem reifica o caráter de vigilância do aconselhamento instrução cujo encontro do profissional com o usuário pode ficar restrito ao cumprimento de metas que atendam aos interesses políticos da gestão municipal. Muitas vezes, a quantidade de pessoas testadas é utilizada como indicador de resposta ao HIV/aids.

Assim, se para as diversas instâncias de gestão os indicadores são organizados em torno de aspectos quantitativos, o aconselhamento instrução parece estar a serviço da manutenção desse quadro que concebe o indivíduo como responsável por sua condição sorológica; que mudanças a favor da redução dos índices de infecção pelo HIV dependem de alteração no comportamento das pessoas; que profissionais de saúde são agentes do biopoder.

É importante pontuar que as entrevistadas expressam algum descontentamento com essa realidade que negligencia o aconselhamento. Mas, de forma geral, as queixas não parecem assumir status de formulações criativas para as situações. Isso sugere que, na rotina do trabalho, as tensões e conflitos se impõem de tal modo aos profissionais de saúde, que eles não conseguem encontrar mediações, saídas efetivas. Em que pese as aparentes críticas expressas pelos profissionais, na lógica do aconselhamento instrução, eles se mantêm como agentes de regulação e controle da população, já que os questionamentos são limitados às dificuldades em torno do objetivo de informar, orientar, educar e promover mudança de comportamento dos usuários. Além disso, não indicam alterações significativas na dinâmica do trabalho e no aconselhamento propriamente dito. Aconselhadores nessa perspec- 
tiva, mesmo sendo aparentemente críticos, não conseguem construir saídas significativas para a realidade em que atuam. Reflexões sobre a realidade dos trabalhadores em saúde e as dificuldades de alteração dela, têm sido feitas por Campos (2009), cujas contribuições indicam necessidade de postura crítica diante da clínica, de um modo geral, e da saúde pública.

Além disso, a primazia da testagem em detrimento do aconselhamento parece consonante com a própria construção da concepção de risco em epidemiologia, cuja implicação com métodos analítico-quantitativos tem deixado de lado importantes articulações com outras áreas de conhecimento "como as Humanidades e os procedimentos compreensivo-interpretativos" (Ayres, 2011, p. 1309).

No aconselhamento relação percebemos aproximação com a noção de vulnerabilidade. Esta tem orientado o modo de se considerar a questão do HIV-Aids, tanto por cientistas, quanto por gestores e profissionais de saúde (Ayres et al., 2003; Parker, 2000), ao contribuir com avanços significativos na abordagem da noção de risco, já que abrange análise da complexidade das situações (Almeida, Castiel, \& Ayres, 2009).

A ideia de que o aconselhamento se constrói no próprio momento da relação profissional-usuário, parece confrontar referenciais hegemônicos do campo em questão. Destitui a centralidade do saber do profissional e orientação programática da intervenção, elementos caros ao modelo biomédico em saúde. Questiona a personificação, no indivíduo, das causas e condições da infecção pelo HIV. Na contramão daquela perspectiva individualizante, o aconselhamento relação concebe o sujeito inscrito numa história, reconhece valores que marcam a realidade social na qual se dão as trocas afetivas e sexuais que o envolve.

Nessa direção contra hegemônica do aconselhamento, o sujeito é considerado como ativo na condução de sua saúde. As dificuldades que, por ventura possam se apresentar na adoção de práticas sexuais protetivas, relacionam-se à sua própria inscrição no mundo, a como estabelece relações, vínculos e com quais valores sociais é instado a lidar.
Esse aspecto identificado no aconselhamento relação sugere que aconselhadores têm lidado de algum modo, com abordagem construcionista da sexualidade (Paiva, 2008), já que rejeitam o uso de referência biológica, essencialista para se tratar a sexualidade, típica da perspectiva sexológica. Ao contrário, de acordo com as análises, as entrevistadas expressam ideias de que a sexualidade é tecida na dinâmica das relações sociais. Estas envolvem os sujeitos e suas relações em teias simbólicas que guardam relações de poder e classificações hierarquizadas dos sexos (homem e mulher) e dos gêneros (masculino e feminino).

O aconselhamento relação rejeita, então, noções como individualização, interiorização, em sua concepção de sujeito. Ousamos nomeá-lo de sujeito-complexo ou sujeito-cidadão. Complexo porque atravessado por dimensões diversas, como a econômica, política, religiosa, de modo que apreendê-lo pode ser tarefa inócua, sendo mais estratégico, a partir da relação, do diálogo, identificar/lidar com referenciais da sua realidade. Cidadão porque o aconselhamento relação acolhe a diversidade, a singularidade, o que sugere respeito às diferenças e compromisso com os direitos humanos e a promoção/fortalecimento da cidadania. "O que está em pauta, de maneira decisiva, é o reconhecimento [grifo do autor] de que existem múltiplas possibilidades legítimas de constituição do sujeito e de que diferentes formas éticas de subjetivação são também possíveis" (Birman, 1994, p. 114).

A complexidade que envolve o aconselhamento relação é elemento com o qual lidam os profissionais de saúde, em sua rotina. Consideram que o trabalho junto ao usuário, em sua dimensão micropolítica, está intimamente relacionado com aspectos macrossociais da realidade. Alocação de recursos financeiros, posicionamentos políticos em relação a recursos humanos para a saúde, formatação de políticas, como as que orientam a oferta de teste anti-HIV e aconselhamento, engendram fluxos de trabalho e rotina para os quais os profissionais de saúde têm encontrado posicionamentos produtivos, nos quais o usuário é prioridade. Isto é, os aconselhadores produzem mediações eficazes 
para lidar com a complexidade de questões que envolvem sua rotina.

Nessa perspectiva, o aconselhamento inscreve-se como prática em saúde que integra a complexidade da realidade que envolve o HIV-aids e a construção de respostas efetivas para esta epidemia, em nome da promoção de saúde. Vale à pena esclarecer que os modos de aconselhar identificados na análise das entrevistas - o instrução e o relação - não se constituem em modelos fixos. De forma geral, não se pode associá-los aos aconselhadores, como se estes fossem representantes de um determinado modo de aconselhar. Ao contrário, os profissionais de saúde transitam entre esses modos, ora assumindo práticas típicas do aconselhamento instrução, ora atuando de acordo com o aconselhamento relação. Talvez, ao apreender a complexidade da prática do aconselhamento podemos supor que estejamos na direção de uma "clínica contemporânea do HIV/Aids", conforme anunciado por Bastos (2006); de práticas cotidianas, no campo da saúde, implicadas com a dimensão ético-política (Spink, 2010).

\section{Considerações Finais}

Os modos de aconselhar identificados na pesquisa informam sobre o dispositivo do aconselhamento na perspectiva dos entrevistados. $\mathrm{O}$ aconselhamento instrução parece assumir contornos de um discurso hegemônico com elementos que sugerem concentração de saber e poder no profissional de saúde e ênfase no caráter informativo que define a direção dos procedimentos. Nessa lógica, profissional e usuário são distintos e posicionados hierarquicamente. $\mathrm{O}$ aconselhamento relação aparece mais sutilmente, podendo a ele ser identificado o status de contra hegemônico, sendo-lhe característico o diálogo entre profissional e usuário e a ausência de modelo protocolar que se imponha à relação propriamente dita. Apresenta quadro sugestivo de horizontalidade na relação e, por conseguinte, uma prática mais democrática.

Identificamos como tendência, que no modo instrução o usuário tende a ser reduzido como responsável/culpado por sua saúde, ou como um índice, contabilizado na quantidade de testes anti-HIV realizados. Já no modo relação outros elementos, para além do indivíduo, são acionados para se problematizar a eficácia e eficiência do aconselhamento. Aspectos relacionados à gestão do CTA, bem como à política municipal de DST-HIV/aids, além das direções que tomam as políticas estaduais e federal no enfrentamento da aids e aspectos de ordem social, cultural, econômica, religiosa, que atravessam as práticas sociais e engendram modos de subjetivação, são levados em conta, em maior ou menor grau de complexidade, no trabalho dos profissionais.

Cabe-nos problematizar, nesse quadro analítico construído na pesquisa, sobre dois aspectos presentes no cenário do aconselhamento e que consideramos estratégicos no que se refere à discussão sobre o enfrentamento da aids. Trata-se do debate sobre risco e do debate sobre sexualidade.

No caso da noção de risco, por exemplo, referenciais de perspectiva higienista, que datam do século XVIII (Ayres, 2011), apresentam-se nas entrevistas, como orientadoras da prática do aconselhamento. Perspectiva que responsabiliza e culpabiliza os sujeitos por sua condição sorológica também estão presentes no material.

A construção social do conceito de risco tem sido problematizada por vários autores que destacam aspectos importantes nesse campo. Num plano mais geral, diz-se que vivemos numa sociedade de riscos (Le Breton, 2009), lidando com ameaças em todas as esferas. O sentimento de insegurança é globalizado e as possibilidades de ameaça atingem a todas as pessoas, em diversas circunstâncias. Esforços para gerir todos os riscos que nos ameaçam colocam-nos diante de uma cultura da ansiedade (Castiel, 2011), de monitoramento da realidade e autovigilância, no sentido prevencionista.

À primeira vista, a possibilidade de infecção pelo HIV se constitui uma dessas ameaças atuais para as quais é indispensável postura segura. Essas construções em torno da categoria risco são, entretanto, datadas. Herança da modernidade e da pretensão iluminista de conhecimento pleno e controle (Almeida et al., 2009; Ayres, 2007, 2011; Le Breton, 2009; Rios et al., 2008), essa 
perspectiva instrumental de risco parece desconsiderar dimensões não previsíveis da existência, isto é, a contingência mesmo da vida.

José Ricardo Ayres (2011, pp. 1309-1310) ao mesmo tempo em que reconhece a importância da Epidemiologia do Risco, em contribuir com possibilidades "preventivas e curativas das práticas de saúde contemporâneas", pelo uso de ferramentas estatísticas, identifica dificuldades dos conhecimentos epidemiológicos em "lidar concretamente com os processos de saúde e doença", caso se fixe no rigor matemático das projeções e probabilidades e não considere "aspectos subjetivos, relacionais, simbólicos e valorativos".

Nessa direção é que tem sido sugerido o conceito de risco contingencial como alternativo aos conhecidos sentidos de risco utilizados na literatura - risco como perigo; risco individual; risco populacional; risco estrutural. A ideia de risco contingencial abrange a complexidade da vida e deve ser complementada por conceitos como o de vulnerabilidade (Almeida et al., 2009).

O conceito de vulnerabilidade tem possibilitado interessante revisão da ideia de risco, ao colocar-se como saber mediador, diante o qual, os sujeitos e grupos envolvidos participam do gerenciamento das práticas em saúde. Enquanto a noção mais ortodoxa de risco - numa perspectiva instrumental e de controle - consegue mostrar quem, onde e quando o risco se apresenta, o conceito de vulnerabilidade possibilita entender o porquê da situação em questão, já que envolve aspectos políticos, sociais, psicoafetivos, éticos, culturais (Almeida et al., 2009).

A abordagem da questão do risco de infecção pelo HIV, portanto, na prática do aconselhamento, merece muito cuidado, no sentido de que o profissional pode estar se posicionando a serviço da vigilância e controle dos indivíduos, o que os manteria reféns de determinações alheias sobre sua própria saúde. A noção de risco contingencial constitui interessante ferramenta para o trabalho do profissional de saúde, já que possibilita a emergência do usuário como sujeito ativo no seu autocuidado.

O outro aspecto problematizado diz respeito à abordagem da sexualidade, no encontro entre profissionais de saúde e usuários. A presença de abordagem construcionista e não apenas sexológica no tratamento de questões que envolvem a sexualidade, sugere postura produtiva na prática profissional em HIV-aids, conforme discute Vera Paiva (2008). Na perspectiva construcionista a relação homem-mulher e a submissão desta às determinações do parceiro, merecem ser pensadas criticamente. O machismo e a dependência financeira da mulher em relação ao parceiro são citados, pelos entrevistados, como elementos presentes em como se decide pelo uso ou não do preservativo. Nesses casos, a decisão concentra-se no homem que se impõe à parceira, respaldado pela construção cultural do patriarcado, que desde a fundação da nossa sociedade tem sido imposta para organizar relações entre os sexos e os gêneros.

Ainda que essa direção apoiada em abordagem construcionista tenha sido identificada no material analisado percebemos certa fragilidade por parte dos profissionais em como manejar essas questões. Não identificamos no material das entrevistas, referência a um tratamento mais efetivo da sexualidade, no momento do aconselhamento. As entrevistas problematizam que a sexualidade é uma construção social (coerente com a abordagem construcionista), mas as aconselhadoras parecem não dispor de recursos para utilizarem no diálogo com o usuário à sua frente. Experiências positivas nesse sentido são apresentadas por Vera Paiva $(2002,2008)$ que, a partir de influências de Jacob Moreno, Paulo Freire e Augusto Boal, tem utilizado a noção de script para trabalhar com indivíduos e grupos, o que tem permitido ampliar detalhes da vida cotidiana, decodificar desejos, experiências prévias, recursos pessoais e comunitários, descobrir personagens onipresentes (pais, ex-parceiros, o pastor da igreja), ou crenças e valores encarnados em personagens. Permitirá também identificar desigualdades, relações de poder, avaliar o acesso à informação, a insumos, a serviços e observar o desrespeito ou violação de direitos relevantes em diversos cenários, palcos e interações intersubjetivas (Paiva, 2008, p. 649).

Pesquisas futuras que tenham como objeto a investigação do manejo das questões envol- 
vendo a sexualidade, no aconselhamento, na realidade de Pernambuco, merecem investimento. O elemento cultural implicado nesse debate convida-nos à formulação de conhecimentos e dispositivos de intervenção implicados com a realidade da população em foco.

Vale à pena pontuar que as aconselhadoras não se referem, de forma geral, à acolhida $\mathrm{e}$ escuta, em sua rotina, de pessoas com práticas homossexuais e/ou bissexuais. Estariam as entrevistadas reproduzindo a cultura de heteronormatividade, que em nossa realidade é bastante próxima de práticas e referências homofóbicas? A solicitação para que as entrevistadas falassem de sua experiência, no momento em que ocorreu o diálogo com a pesquisadora, não condicionou que fossem relatadas situações que envolvesse apenas relações heterossexuais. Entretanto, essas tomaram a grande parte das narrativas. Investigar esse aspecto pode ser também objeto de atenção de futuros estudos. Para tanto, pode-se lançar mão de metodologias de observação e etnografias, coerentes com a questão em foco.

A pesquisa sinaliza para um dos grandes desafios no campo do enfrentamento do HIV/ Aids, o de formar profissionais que incorporem em suas práticas, a lógica da construção social da relação saúde-doença e, assim, distanciem-se de procedimentos de vigilância e controle. Que se disponham a colocar em questão suas próprias concepções em torno de risco, sexualidade, prevenção e se exponham à literatura científica que vem sendo construída em torno desses conteúdos; bem como assumam como tarefa a partilha de experiências, inquietações, exposição a pares, direção produtiva na própria formação e qualificação do serviço prestado. Como minimizar as distâncias entre a formulação de conhecimentos, a elaboração da política e sua execução, também merece ser objeto de atenção na formação de aconselhadores.

A prática do aconselhamento, enfim, inscreve-se num campo de forças que, no caso analisado, tem no aconselhamento instrução a construção hegemônica, enquanto que o aconselhamento relação se constitui como linha de fuga, ou seja, de rupturas do instituído. Reconhecer essa dinâmica, identificar o jogo instituído/ instituinte, isto é, elaborar conhecimentos sobre essa realidade se constitui em tarefa para todos pesquisadores, gestores, profissionais de saúde. Talvez assim, poderemos construir indicações para dispositivos de intervenção que sejam, de fato, comprometidos com a reversão de quadros de opressão e desigualdades sociais. Com essa pauta em foco, certamente possamos contribuir para práticas de respeito aos direitos humanos, aos direitos sexuais e aos valores democráticos.

\section{Referências}

Almeida, N., Filho, Castiel, L. D., \& Ayres, J. R. (2009). Riesgo: concepto básico de la epidemiología. Salud Colectiva, 5(3), 323-344.

Araújo, C. L. F., \& Camargo, K. R., Jr. (2004). Aconselhamento em DST/HIV: Repensando conceitos e práticas. Rio de Janeiro, RJ: Folha Carioca.

Ayres, J. R. C. M. (2007). Risco, razão tecnológica e o mistério da saúde. Interface - Comunicação, Saúde, Educação, 11(21), 145-163.

Ayres, J. R. C. M. (2011). Desenvolvimento histórico-epistemológico da Epidemiologia e do conceito de risco. Cadernos de Saúde Pública, 27(7), 1301-1311.

Ayres, J. R. C. M., França, I., Jr., Calazans, G. J., \& Saletti, H. C., Filho (2003). Conceito de Vulnerabilidade e as Práticas de Saúde: Novas perspectivas e desafios. In D. Czeresnia \& C. M. Freitas (Orgs.), Promoção da Saúde: Conceitos, reflexões, tendências (pp. 117-139). Rio de Janeiro, RJ: Editora da Fundação Oswaldo Cruz.

Bardin, L. (1977). Análise de Conteúdo. Lisboa, Portugal: Edições 70.

Bastos, F. I. (2006). Aids na Terceira Década. Rio de Janeiro, RJ: Editora da Fundação Oswaldo Cruz.

Birman, J. (1994). A sexualidade entre o mal e as maledicências. In M. A. Loyola, Aids e Sexualidade. O ponto de vista das ciências humanas (pp. 109-115). Rio de Janeiro, RJ: Relume-Dumará.

Campos, G. W. S. (2009). Considerações sobre a arte e a ciência da mudança: Revolução das coisas e reforma das pessoas. O caso da saúde. In S. R. Carvalho, M. E. Barros, \& M. S. Ferigato, Conexões: Saúde coletiva e politicas de subjetividade. São Paulo, SP: Aderaldo \& Rothschild.

Castiel, L. D. (2011). Saúde, riscos e hiperprevenção. Acta Paulista de Enfermagem, 24(4), 34-35. 
Corrêa, M. (1994). Medicalização social e a construção da sexualidade. In M. A. Loyola, Aids e Sexualidade. O ponto de vista das ciências humanas (pp. 117-140). Rio de Janeiro, RJ: Relume-Dumará.

Denzin, N. K., \& Lincoln, Y. S. (2006). O Planejamento da pesquisa qualitativa: Teorias e abordagens. Porto Alegre, RS: Artemed.

Deslandes, S. F., \& Gomes, R. (2004). A pesquisa qualitativa nos serviços de saúde: Notas teóricas. In L. M. Bosi \& F. Mercado-Martinez (Orgs.), Pesquisa qualitativa de serviços de saúde (pp. 99-120). Petrópolis, RJ: Vozes.

Ferreira, J. L., Neto (2011). Subjetividade e Território: Para além da interioridade. In J. L. Ferreira Neto, Psicologia, Políticas Públicas e o SUS (pp. 51-76). São Paulo, SP: Escuta.

Filgueiras, S. L., \& Deslandes, S. F. (1999). Avaliação das ações de aconselhamento. Análise de uma perspectiva de prevenção centrada na pessoa. Cadernos de Saúde Pública, 15(Sup. 2), 121-131.

Foucault, M. (2007a). Sobre a história da sexualidade. In M. Foucault, Microfísica do Poder (24. ed.). Rio de Janeiro, RJ: Graal.

Foucault, M. (2007b). A governabilidade. In M. Foucault, Microfísica do Poder (24. ed.). Rio de Janeiro, RJ: Graal.

Galindo, W. C. M. (2008). Intervenção Rural e Autonomia: A experiência da Articulação no Semi-árido/ASA em Pernambuco. Recife, PE: Editora Universitária da Universidade Federal de Pernambuco.

Grüner, E. (Coord.). (2011). Nuestra América y el Pensar Crítico: fragmentos del pensamiento crítico de Latinoamérica y del Caribe. Buenos Aires, Argentina: Consejo Latinoamericano de Ciencias Sociais.

Kelle, U. (2002). Análise com auxílio de computador: Codificação e indexação. In M. W. Bauer \& G. Gaskell (Eds.), Pesquisa qualitativa com texto, imagem e som: Um manual prático (P. A. Guareschi, Trad., pp. 393-415). Petrópolis, RJ: Vozes.

Le Breton, D. (2009). Condutas de risco: Dos jogos de morte ao jogo de viver (L. L. de Oliveira, Trad.). Campinas, SP: Autores Associados.

Merhy, E. E. (2007). Saúde: A cartografia do trabalho vivo (3. ed.). São Paulo, SP: Hucitec.
Mészaros, I. (2004). O poder da ideologia. São Paulo, SP: Boitempo Editorial.

Ministério da Saúde. (1993). Normas de Organização e Funcionamento dos Centros de Orientação e Apoio Sorológico. Brasília, DF: Autor.

Ministério da Saúde. (1998). Aconselhamento em DST, HIV e Aids: Diretrizes e procedimentos básicos (3. ed.). Brasília, DF: Autor.

Ministério da Saúde. (1999). Diretrizes dos Centros de Testagem e Aconselhamento - CTA: Manual. Brasília, DF: Autor.

Ministério da Saúde. (2003). Aconselhamento em DST/HIV/Aids para a atenção básica. Brasília, DF: Autor.

Ministério da Saúde. (2010). Diretrizes para Organização e Funcionamento dos CTA do Brasil. Brasília, DF: Autor.

Monteiro, J. F. A., \& Figueiredo, M. A. C. (2009). Vivência profissional: Subsídios à atuação em HIV/ Aids. Paideia (Ribeirão Preto), 19(42), 67-76.

Paiva, V. (2002). Sem mágicas soluções: A prevenção e o cuidado em HIV/AIDS e o processo de emancipação psicossocial. Interface - Comunicação, Saúde, Educação, 6(11), 25-38.

Paiva, V. (2008). A Psicologia redescobrirá a sexualidade? Psicologia em Estudo, 13(4), 641-651.

Parker, R. (2000). Na contramão da Aids: Sexualidade, intervenção, política. Rio de Janeiro, RJ: Associação Brasileira Interdisciplinar de AIDS.

Rios, L. F., Paiva, V., Maksud, I., Oliveira, C., Cruz, C. M. da S., Silva, C. G da T. V., Jr., \& Parker, R. (2008). Os cuidados com a "carne" na socialização sexual dos jovens. Psicologia em Estudo, 13(4), 673-682.

Santos, B. S. (2000). A crítica da razão indolente: Contra o desperdício da experiência. São Paulo, SP: Cortez.

Santos, B. S. (2010). A Gramática do Tempo: Para uma nova cultura política. (3. ed., Vol. 4). São Paulo, SP: Cortez.

Santos, D. F. (2009). HIV/aids e os médicos em formação: Aprendendo a cuidar de vírus ou pessoas? In K. R. Camargo Jr. \& M. I. Nogueira, Por uma filosofia empírica da atenção à saúde: Olhares sobre o campo biomédico. Rio de Janeiro, RJ: Editora da Fundação Oswaldo Cruz.

Santos-Filho, S. B. (2009). Um olhar sobre o trabalho em saúde nos marcos teórico-políticos da saúde 
do trabalhador e do HumanizaSUS: O contexto do trabalho no cotidiano dos serviços de saúde. In S. B. Santos-Filho \& M. E. B. Barros, Trabalhador da Saúde - Muito Prazer! Protagonismo dos trabalhadores na Gestão do Trabalho em Saúde. Ijuí, RS: Ed. Ijuí.

Souza, V., \& Czeresnia, D. (2007). Considerações sobre os discursos do aconselhamento nos centros de testagem anti-HIV. Interface-Comunicação, Saúde, Educação, 11(23), 531-548.

Spink, M. (2010). J. Psicologia Social e Saúde: Trabalhando com a complexidade. Quaderns de Psicologia, 12(1), 41-56.
Traverso-Yépez, M. (2008). A Psicologia Social e o Trabalho em Saúde. Natal, RN: Editora da Universidade Federal do Rio Grande do Norte.

Turato, E. R. (2003). Tratado de metodologia da pesquisa clínico-qualitativa (2. ed.). Petrópolis, RJ: Vozes.

Recebido: $13 / 07 / 2013$

$1^{a}$ revisão: 17/10/2012

Aceite final: 26/02/2013 